\title{
Correction: TCR-like CARs and TCR-CARs targeting neoepitopes: an emerging potential
}

Mansour Poorebrahim (ID - Niloufar Mohammadkhani • Reza Mahmoudi • Monireh Gholizadeh • Elham Fakhr • Angel Cid-Arregui

Published online: 24 March 2021

(c) The Author(s), under exclusive licence to Springer Nature America, Inc. 2021

Correction to: Cancer Gene Ther

https://doi.org/10.1038/s41417-021-00307-7

Following publication of this article, the authors contacted the journal to request the correction for the placement of references 17 and 18 . The reference 17 should be cited in the same place with reference 16. Instead, reference 18 should be cited in the current position of reference 17.

This has now been corrected in both the PDF and HTML versions of this article. 